\title{
Creative Reading Terhadap Dongeng Untuk Penulisan Puisi
}

\author{
Pana Pramulia \\ panapramulia@unipasby.ac.id \\ Program Studi Guru Sekolah Dasar \\ Universitas PGRI Adi Buana Surabaya
}

\begin{abstract}
Abstrak
Menulis karya sastra, khususnya puisi membutuhkan kecermatan dalam memotret realitas dan harus memiliki pengetahuan kompleks tentang kehidupan, serta penulis puisi harus mempunyai daya perenungan yang kuat. Artinya, penulis puisi atau penyair dituntut sebagai pembaca aktif, karena dari pembacaan aktif penyair akan mempunyai pengetahuan yang holistik. Bagi penulis puisi pemula, menulis puisi merupakan hal yang tidak mudah, maka dibutuhkan teknik khusus. Salah satu teknik yang dapat digunakan, yaitu teknik creative reading. Teknik creative reading adalah teknik membaca untuk melahirkan kembali sebuah teks setelah pembaca mengalami transformasi. Teknik tersebut digunakan mahasiswa PGSD Unipa Surabaya angkatan 2014 untuk menulis puisi berdasarkan pembacaan dongeng secara intensif. Pengumpulan data pada penelitian ini dilakukan dengan dua model, yaitu dalam bentuk hard file (kertas) dan soft file yang dikirimkan ke surat elektronik. Karya puisi mahasiswa setelah menggunakan teknik creative reading dikatakan baik, karena dapat memahami tahapan dan karakter teknik tersebut dengan baik pula.
\end{abstract}

Kata kunci: Creative Reading, Dongeng, Puisi

\section{PENDAHULUAN}

Menulis karya sastra, termasuk puisi berangkat dari fenomena realitas yang terjadi di masyarakat. Seorang penyair memotret fenomena yang terjadi, merenungkannya, dan menulis kembali fenomena tersebut dalam bentuk puisi. Menulis puisi memang tidak mudah dibandingkan bentuk karya sastra yang lain (prosa dan naskah drama), karena bahasa puisi padat dan penuh kata-kata kiasan. Selain itu, bagi pembaca awam, memahami puisi juga tidak mudah. Memahami puisi harus memiliki pengetahuan yang kompleks serta kebiasaan membaca banyak puisi. Berdasarkan hal tersebut, penulis puisi atau penyair harus mempunyai pengetahuan yang holistik tentang kehidupan dan juga harus sebagai pembaca yang aktif. Pramulia (2017:68) menyatakan untuk memahami nilai-nilai kehidupan, seseorang harus melakukan pengamatan dan perenungan secara mendalam.

Puisi merupakan salah satu cabang sastra yang menggunakan kata-kata sebagai media penyampaian untuk membuahkan ilusi dan imajinasi, seperti halnya lukisan yang menggunakan garis dan warna untuk menggambarkan gagasan (Aminudin, 2013:134). Artinya, kata-kata yang terdapat dalam puisi menggambarkan ekspresi penyair yang diuraikan melalui kiasan atau simbolis. Dari sini dapat dikatakan, bahwa kata-kata kiasan dan simbolis langsung berkaitan dengan keindahan yang dimiliki puisi. Di sisi lain, puisi tidak hanya indah, tetapi juga harus menyampaikan pesan kebaikan dan atau kritik terhadap kehidupan. Itulah mengapa, karya sastra juga dianggap sebagai pengajaran jiwa bagi masyarakat.

Berdasarkan penjelasan di atas, puisi mempunyai beberapa aspek yang harus dipahami. Sutejo dan Kasnadi (2009:1) menyebutkan aspek puisi di antaranya (1) aspek pendidikan; (2) aspek sosial budaya; (3) aspek sosial masyarakat; (4) aspek politik; (5) aspek ekonomi; dan (6) aspek adat. Satu puisi paling tidak memuat satu aspek tersebut untuk memberi pesan kepada pembaca. Dari sini, 


\section{Pana Pramulia}

penyair harus tepat memasukkan pesan kepada pembaca sasarannya. Misalnya, jangan sampai puisi yang ditujukan kepada anak-anak memuat pesan yang tidak sesuai dengan jiwa dan moral anak-anak. Penulis puisi untuk anak-anak hendaknya mengetahui kebutuhan anak-anak dan apa yang harus dilakukan untuk menumbuhkan karakter anak.

Menengok masyarakat Indonesia masa lalu, memberi pengajaran moral dan nilai kiehidupan kepada anak dengan cara bercerita, seperti mendongeng. Masyarakat Indonesia berada dalam tradisi kelisanan yang kuat (Sugihastuti, 2011:93). Pada masa sekarang pengajaran kepada anak membutuhkan media yang tepat, yang salah satu media tersebut bisa dalam bentuk puisi yang merupakan transformasi dari dongeng. Mengapa puisi hasil transformasi dari dongeng yang digunakan? Pertama, penulis puisi merupakan penulis pemula, yaitu Mahasiswa PGSD Angkatan 2014 yang memilih Mata Kuliah Kreativitas Sastra Anak. Penulis pemula cenderung kesulitan memotret fenomena yang terjadi di masyarakat, karena belum adanya kebiasaan. Kedua, pesan atau amanat yang terdapat dalam dongeng tepat digunakan sebagai media pengajaran anak. Pesan-pesan yang terdapat dalam dongeng menjadi fokus utama. Ketiga, dongeng mudah diakses, baik secara lisan (dari orang tua) maupun di dunia maya.

Secara teknis, mahasiswa yang ditugasi tersebut mencari serta memilih dongeng Indonesia. Kemudian, dongeng yang sudah dipilih dibaca dan dipahami isi serta amanatnya. Mahasiswa diminta untuk membaca dongeng secara berulang-ulang dan kemudian diminta untuk menggunakan teknik creative reading. Teknik tersebut merupakan teknik membaca pemahaman teks secara mendalam, baik isi maupun bentuk. Creative reading merupakan cara membaca untuk melahirkan kembali sebuah teks setelah pembaca mengalami transformasi (Dewi, 2006:26). Maksdunya, setelah menggunakan teknik creative reading ini, mahasiswa akan mempunyai ide untuk menuliskan kembali dongeng tersebut ke dalam bentuk puisi.

Creative reading merupakan tahapan terakhir dalam membaca setelah informative reading, interpretative reading, dan critical reading. Jika, seseorang ingin menggunakan teknik creative reading, maka harus melewati tiga tahapan sebelumnya. Creative reading dilakukan jika informative reading, interpretative reading, dan critical reading sudah tuntas digunakan oleh pembaca. Tahapan reading (membaca) tersebut, maksudnya pada langkah pertama pembaca mengumpulkan informasi penting mengenai teks yang dibaca, langkah kedua pembaca memberi interpretasi terhadap informasi yang telah dikumpulkan, langkah ketiga pembaca mencari makna informasi dari teks tersebut, dan langkah keempat pembaca mencari pesan terselubung, mencatat kata-kata kunci, dan menemukan kata-kata kiasan dan simbolis. Setelah tahap keempat (creative reading) selesai, maka segala sesuatu yang sudah tercatat tersebut dapat digunakan sebagai bahan pijakan untuk mentransformasikan teks asli ke dalam bentuk lain. Tujuannya, pembacaan harus sampai pada kemampuan menghadirkan kembali teks dengan bentuk yang berbeda agar makna dan pesan mudah dipahami. Kiranya cara tersebut dapat dikatakan mudah dan bisa diterapkan untuk penulis puisi pemula.

Di sisi lain, puisi-puisi dari mahasiswa angkatan 2014 pada mata kuliah Kreativitas Sastra Anak yang ditulis berdasarkan teknik creative reading diterbitkan menjadi sebuah antologi bersama. Buku antologi bersama tersebut berjudul "Sahabat Sampai Surga" yang diterbitkan oleh Pagan Press pada Bulan Juli 2018 dengan ISBN 978-602-0891-98-9.

\section{METODE PENELITIAN}

Berdasarkan faktor-faktor yang telah diuraikan, peneliti menetapkan setting penelitian atau latar yang dapat memenuhi tuntutan dalam sebuah penelitian. Pertama, pemilihan mata kuliah Kreativitas Sastra Anak, karena pada tahun akademik 2017/2018 semester genap peneliti mengampu mata kuliah Kreativitas Sastra Anak di Program Studi PGSD. Kedua, mata kuliah Kreativitas Sastra Anak merupakan mata kuliah pilihan untuk Angkatan 2014 yang mahasiswanya berjumlah 38 dan hanya satu kelas. Dengan jumlah 38 mahasiswa dan hanya satu kelas tersebut, peneliti cenderung mudah untuk menerapkan teknik creative reading dan juga mudah untuk mengontrol karyanya. 


\title{
Pana Pramulia
}

Teknik pengumpulan data menggunakan cara mahasiswa mengumpulkan tugas atau karya yang sudah ditulis, baik sebelum menggunakan maupun setelah menggunakan teknik creative reading. Pengumpulan tugas dilakukan dengan dua model, yaitu dalam bentuk hard file (kertas) dan soft file yang dikirimkan ke surat elektronik panapramulia@unipasby.ac.id. Tujuan pengiriman tugas dengan dua model tersebut, yakni untuk mengantisipasi hilangnya hard file.

Data yang sudah terkumpul kemudian dianalisis (Permana, 2015). Analisis data yang akan dilakukan yaitu dengan membandingkan karya puisi mahasiswa sebelum menggunakan teknik creative reading dan setelah menggunakan teknik creative reading. Aspek yang akan dianalisis dari karya puisi mahasiswa tersebut merujuk pada ketepatan mengambil pesan, kata-kata kiasan atau simbolis, dan ketepatan mengambil kata-kata kunci dari dongeng yang dipilih. Selain itu, aspek kesesuaian bahasa dengan usia anak serta aspek keindahan juga termasuk dalam analisis data. Puisi yang dihadirkan dalam hasil dan pembahasan akan dipilih secara acak dan hanya tiga puisi yang disajikan. Hal tersebut disebabkan, terbatasnya halaman dan peneliti memprediksikan puisi dari mahasiswa berdasarkan teknik creative reading akan baik.

\section{HASIL DAN PEMBAHASAN}

Tugas pertama mahasiswa sebelum mencari, membaca, dan memahami dongeng, yaitu menulis satu puisi yang kemudian dikumpulkan dalam bentuk hard file. Peneliti yang sekaligus dosen membaca dengan cermat hasil karya mahasiswa tersebut sebelum menerapkan teknik creative reading yang kemudian memilih karya terbaik untuk dijadikan model. Karya yang dinilai terbaik dan dijadikan model sebanyak enam karya. Enam puisi dinilai terbaik, karena telah memenuhi keindahan sastra, pemilihan tema, dan pesan yang disampaikan kuat, serta dapat dipahami anak-anak. Puisi tersebut antara lain, Semangat Pagiku (Nur Cahya Ningsih), Ibu Kartini (Dwi Agustin), Indonesia (Jayati Pratiwi), Pelangi (Uci Nurul Hidayati), Hujan (Eva Setianingrum), dan Sekolah (Ghoniyatul Marhumah). Berikut satu puisi dari enam karya mahasiswa yang dinilai terbaik.

\author{
INDONESIA \\ Jayati Pratiwi \\ Indonesia... \\ Kau adalah negara \\ Berdasar pancasila \\ Kau adalah negara \\ Bersemboyan Bhineka Tunggal lka \\ Kau adalah negara \\ Berlimpah Sumber Daya \\ Indonesia... \\ Kau negara agraris yang besar \\ Kau negara maritim yang luas \\ Pesonamu terpancar \\ Layaknya sinar emas \\ Jayalah terus Indonesiaku \\ Ku selalu bangga denganmu.
}

Puisi dari Jayati Pratiwi tersebut mempunyai pesan kuat dan memenuhi kaidah keindahan sastra. Rima yang digunakan pada bait pertama dan ketiga, berpola A-A-A-A, sedangkan pada bait kedua, berpola A-B-A-B. Dengan rima yang demikian, puisi di atas terkesan indah secara irama dan diksi yang dipilih mudah dipahami anak-anak. Selain itu, isi dari puisi dapat dijadikan media untuk menumbuhkan rasa cinta terhadap tanah air. Maka dari itu, puisi dari Jayati Pratiwi merupakan salah 


\section{Pana Pramulia}

satu dari enam puisi yang dijadikan model (contoh) untuk penulisan puisi berikutnya, walaupun puisi berikutnya berpijak pada dongeng.

Pada tahap selanjutnya, mahasiswa diberi tugas untuk mencari dongeng Indonesia. Langkah berikutnya mahasiswa mengumpulkan informasi penting dari dongeng yang dibaca, kemudian memberi interpretasi atau penafsiran terhadap informasi dari dongeng yang telah dikumpulkan. Setelah menafsirkan, mahasiswa mencari makna informasi dari dongeng tersebut, dan terakhir mahasiswa mencari pesan terselubung, mencatat kata-kata kunci, dan menemukan kata-kata kiasan dan simbolis dari informasi yang terdapat dalam dongeng.

Tahapan terakhir dari proses ini, yaitu creative reading, maka informasi, interpretasi, dan segala sesuatu yang sudah tercatat digunakan mahasiswa sebagai bahan pijakan untuk mentransformasikan teks asli ke dalam bentuk lain. Informasi yang diperoleh dan sudah dicatat dalam dongeng ditransformasikan ke dalam bentuk puisi. Puisi-puisi yang sudah ditulis berdasarkan teknik creative reading tersebut, dalam bentuk hard file (kertas) dan soft file yang dikirimkan ke surat elektronik panapramulia@unipasby.ac.id untuk dikoreksi lebih lanjut. Berikut tiga puisi dari mahasiswa berdasarkan teknik creative reading terhadap dongeng yang dipilih secara acak.

\section{TEMAN SEPERJUANGAN}

Hesti Verdiana

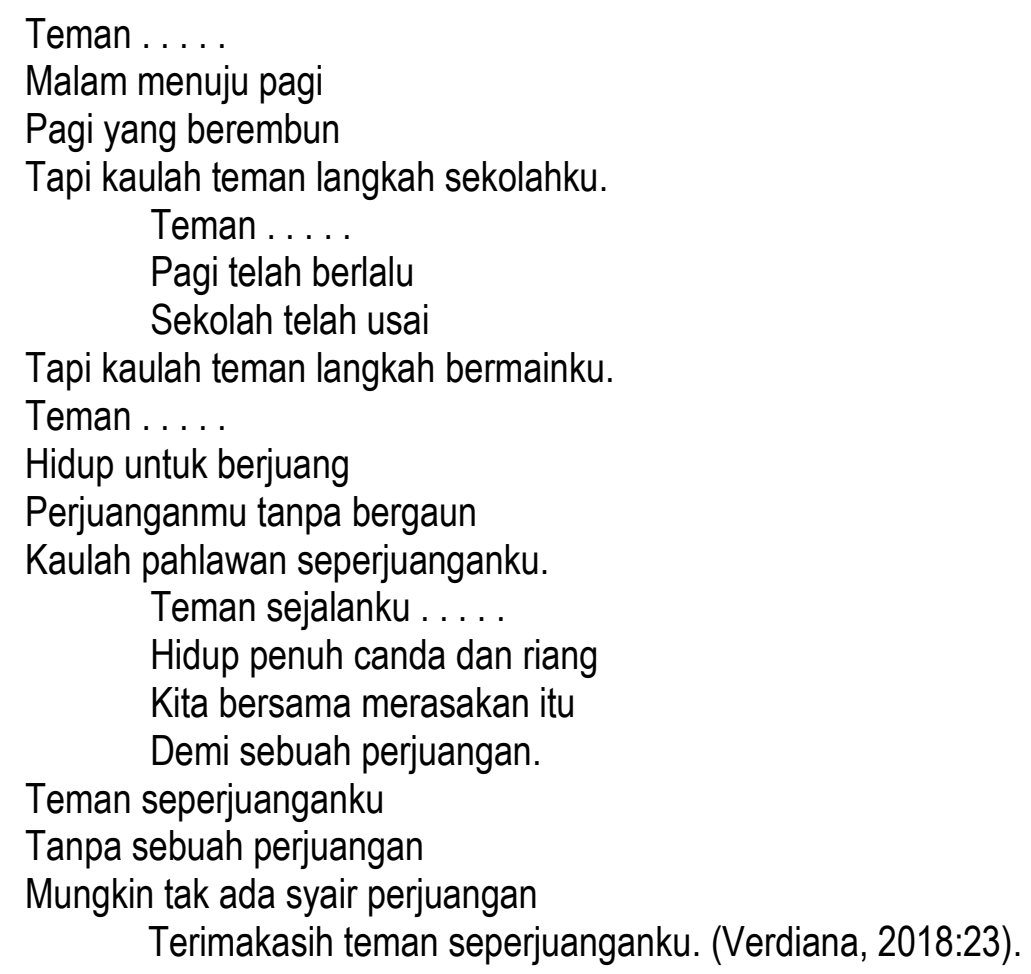

Puisi di atas merupakan hasil transformasi dari dongeng berjudul "Merpati yang Baik Hati" yang diambil dari laman situs Ardiansyah (2015). Hesti Verdiana mencatat dengan cermat nilai-nilai persahabatan merpati dan induk ayam yang terdapat dalam dongeng "Merpati yang Baik Hati". Nilai dan informasi yang dicatat, kemudian dikembangkan sedemikian rupa, serta dikaitkan dengan kehidupan sehari-hari yang dialami anak-anak. Berdasarkan hal tersebut, maka puisi dari Hesti Verdiana tampak hidup dan dapat mudah dipahami anak-anak. Selain itu, puisi dengan judul "Teman Seperjuangan" tersebut dapat menumbuhkan rasa solidaritas kepada teman. Berikut ini juga puisi yang menceritakan tentang persahabatan. 


\title{
KITA ADALAH SAHABAT
}

Alif Rossiani Waldanie

\author{
Kita ... \\ Dipertemukan tanpa ada rencana \\ Engkaulah penyejuk jiwa \\ Selalu ada di saat suka maupun duka \\ Dan selalu membuat tertawa. \\ Kita adalah sahabat \\ Yang selalu mengerti kekurangan kita \\ Kebahagiaan yang selalu kita rasa bersama \\ Dan melangkah dalam tujuan yang sama. (Waldanie, 2018:77)
}

Puisi di atas karya dari Alif Rossiani Waldanie yang berjudul "Kita Adalah Sahabat". Sebelum menulis puisi tersebut Alif memilih dongeng berjudul "Kancil Menyelamatkan Anak Musang". Alif berhasil mencatat dan menginterpretasikan dengan baik nilai-nilai persahabatan yang terdapat dalam dongeng "Kancil Menyelamatkan Anak Musang", sehingga puisi yang ditulis mempunyai pesan kuat, serta diksi yang dipilih dapat mudah dipahami anak-anak. Selain itu, Alif juga mengaitkan nilai-nilai yang sudah dicacat dengan realitas terkini. Akibatnya puisi yang menceritakan persahabatan tersebut, apabila dibaca tampak tidak dipengaruhi oleh dongeng apapun.

Puisi kedua berjudul "Pelangi" yang ditulis oleh Uci Nurul Hidayati. Puisi tersebut berdasarkan hasil pemotretan informasi dari dongeng berjudul "Putri Tujuh". Uci memotret dialog antara Pangeran Empang Kuala dan Putri Mayang Sari. Dialog tersebut menggambarkan bahwa Pangeran Empang Kuala jatuh cinta kepada Putri Mayang Sari, sehingga bahasa yang digunakan Pangeran mendayudayu. Contoh perkataan Pangeran Empang "Putri wajahmu sungguh cantik, sehingga aku tak ingin memalingkan wajahku walaupun hanya sebentar". Berdasarkan contoh tersebut, Uci dengan baik mentransformasikan keindahan-keindahan yang sudah dicatatnya menjadi sebuah puisi yang indah. Berikut puisisnya.

\section{PELANGI \\ Uci Nurul Hidayati}

Kau hadir di kala hujan redah

Kau hadir dengan segala keindahanmu

Warnamu yang sangatcantik

Membuatku tak ingin berhenti melirik.

Merah, kuning, hijau di langit yang biru

Warna indahmu membuatku semakin terpukau

Di setiap rintik hujan ku selalu menantimu

Menanti hadir indah warnamu.

Pelangi yang indah

Aku ingin menjadi sepertimu

Menjadi warna indah setelah hitam

Menjadi senyum setelah sedih. (Hidayati, 2018:38).

Creative reading yang digunakan mahasiswa Angkatan 2014 PGSD Universitas PGRI Adi Buana Surabaya dapat membantu untuk penulisan puisi. Sebelum menggunakan teknik creative reading, mahasiswa menerapkan teknik informative reading, interpretative reading, dan critical reading. Mahasiswa dapat menerapkan keempat teknik tersebut dengan baik, sehingga puisi-puisi yang ditulis lebih baik daripada puisi sebelumnya (tanpa teknik creative reading). "Lebih baik" di sini bukan hanya 


\section{Pana Pramulia}

diksi yang dipilih maupun tema yang diusung, melainkan pesan dan nilai-nilai yang dimuat dapat dikatakan kuat dan mudah dipahami anak-anak. Di sisi lain, teknik creative reading efektif digunakan oleh para penulis karya sastra pemula, karena tahapan-tahapannya mudah dipahami.

\section{SIMPULAN}

Sebelum diterapkan teknik creative reading, mahasiswa menulis puisi bebas berdasarkan pengalaman pribadinya. Dari tiga puluh delapan mahasiswa, hanya enam puisi yang dinilai baik. Enam puisi yang dinilai baik memenuhi kriteria yang sudah ditentukan, antara lain pemilihan diksi, tema, dan dapat dipahami anak-anak, serta pesan yang disampaikan kuat. Berdasarkan hasil tersebut, diterapkan teknik creative reading agar mahasiswa dalam menulis puisi berikutnya dapat memenuhi kriteria yang sudah ditentukan. Akan tetapi, sebelum teknik creative reading diterapkan, enam puisi terbaik tersebut dijadikan model penulisan berikutnya, karena diksi yang digunakan baik dan pesan kuat.

Pada tahapan teknik creative reading teknik creative reading, mahasiswa mencari dongeng Indonesia. Informasi penting dari dongeng yang dibaca dicatat, kemudian mahasiswa memberi interpretasi agar menemukan nilai-nilai. Setelah melakukan interpretasi, mahasiswa mencari makna yang selanjutnya mencari pesan terselubung, mencatat kata-kata kunci, dan menemukan kata-kata kiasan dan simbolis. Hasil yang dicapai atau karya puisi mahasiswa setelah menggunakan teknik creative reading lebih baik daripada sebelumnya. Dengan menggunakan teknik creative reading diksi yang dipilih, tema yang diusung, pesan dan nilai-nilai yang dimuat dapat dikatakan kuat dan mudah dipahami anak-anak.

\section{DAFTAR RUJUKAN}

Aminudin. 2013. Pengantar Apresiasi Karya Sastra. Cetakan kesepuluh. Bandung: Sinar Baru Algesindo.

Ardiansyah. 2015. https://dongengceritarakyat.com/kumpulan-cerita-dongeng-anak-indonesia/.

Dewi, Novita. 2006. Membaca, Menulis, dan Membaca untuk Menulis: Diagnosis Dini Penulisan Karya Tulis di Fakultas Sastra. Jurnal Susastra 3, Volume 2 Nomor 3 tahun 2006, halaman 20 - 35. Jakarta: Himpunan Sarjana - Kesusastraan Indonesia dan Yayasan Obor Indonesia.

Hidayati, Uci Nurul. 2018. Sahabat Sampai Surga: Puisi dan Cerpen Anak, Antologi Karya mahasiswa Universitas Adibuana Surabaya PGSD 2014. Judul Puisi: Pelangi, halaman 38. Lamongan: Pagan Press.

Permana, E. P. (2015). Pengembangan Media Pembejaran Boneka Kaus Kaki Untuk Meningkatkan

Keterampilan Berbicara Siswa Kelas II Sekolah Dasar. Profesi Pendidikan Dasar, 2(2), 133-140. https://doi.org/10.23917/ppd.v2i2.1648

Pramulia, Pana. (2017). Nilai Moral dalam Antologi Cerpen Karya Mahasiswa PGSD Angkatan 2013 Universitas PGRI Adi Buana Surabaya. Efektor, 4 (1), 68-74. doi:10.29407/e.v4i1.791

Sugihastuti. 2011. Teori dan Apresiasi Sastra. Cetakan IV. Cetakan I tahun 2002. Yogyakarta: Pustaka Pelajar Offset.

Sutejo dan Kasnadi. 2009. Kajian Puisi: Teori dan Aplikasinya. Yogyakarta: Pustaka Felicha.

Verdiana, Hesti. 2018. Sahabat Sampai Surga: Puisi dan Cerpen Anak, Antologi Karya mahasiswa Universitas Adibuana Surabaya PGSD 2014. Judul Puisi: Teman Seperjuangan, halaman 23. Lamongan: Pagan Press.

Waldanie, Alif Rossiani. 2018. Sahabat Sampai Surga: Puisi dan Cerpen Anak, Antologi Karya mahasiswa Universitas Adibuana Surabaya PGSD 2014. Judul Puisi: Kita Adalah Sahabat, halaman 77. Lamongan: Pagan Press. 